\title{
On the Pressure and Temperature Dependence of the Absorption Coefficient of $\mathrm{NH}_{3}$
}

\author{
F. Aousgi, S. Hadded, and H. Aroui \\ Laboratoire de Physique Moléculaire, Ecole Supérieure des Sciences et Techniques de Tunis, 5 Avenue Taha Hussein, Tunis 1008, Tunisia \\ Correspondence should be addressed to F. Aousgi, aousgifethi@yahoo.fr and H. Aroui, haroui@yahoo.fr \\ Received 27 June 2011; Accepted 24 August 2011 \\ Academic Editor: Jean-Valère Naubron \\ Copyright () 2011 F. Aousgi et al. This is an open access article distributed under the Creative Commons Attribution License, \\ which permits unrestricted use, distribution, and reproduction in any medium, provided the original work is properly cited.
}

The effects of pressure and temperature on the absorption coefficient of ammonia $\left(\mathrm{NH}_{3}\right)$ gas self-perturbed and perturbed by nitrogen $\left(\mathrm{N}_{2}\right)$ gas have been measured. We varied the gas pressure from 10 to 160 Torr and the temperature from 235 to $296 \mathrm{~K}$ in order to study the absorption coefficient at the center and the wings of lines in the $v_{4}$ band of $\mathrm{NH}_{3}$. These measurements were made using a high resolution $\left(0.0038 \mathrm{~cm}^{-1}\right)$ Bruker Fourier-transform spectrometer. These spectra have been analyzed using the method of multipressure technique permitting to succeed to an evolution of the absorption coefficient with the pressure and the quantum numbers $J$ and $K$ of the $\mathrm{NH}_{3}$ molecule. The results show that the absorption coefficient varies as a quadratic function of the pressure at the center of a given line. However, it has a linear evolution in the wings of the line. Moreover, the absorption coefficients are inversely proportional to temperature in the wings when $\mathrm{NH}_{3}$ lines are broadened by $\mathrm{N}_{2}$. The retrieved values of these coefficients were used to derive the temperature dependence of $\mathrm{N}_{2}$ broadening $\mathrm{NH}_{3}$ lines. The absorption coefficients were shown to fit closely the well-known exponential law.

\section{Introduction}

The infrared spectroscopic investigations of the atmospheres of stars, planets, and their satellites, using infrared spectroscopy, not only provide valuable information about the chemical elements that they consist of, but also about the horizontal and the vertical distribution of their minor constituents. Due to the complexity of the line profiles used to model the spectral shapes (absorption, broadening, intensity), it is necessary to determine experimentally the line parameters of the spectra in order to test the models being used.

Several studies in the literature have investigated the spectral properties of $\mathrm{NH}_{3}$ in several infrared bands. Aroui et al. [1] have studied the self-broadening and line intensities, Nouri et al. [2] have studied the temperature dependence of pressure broadening, and other authors $[3,4]$ were interested in the absorption coefficient at the line centers of $\mathrm{NH}_{3}$. Experimentally absorption coefficients for broadband ArF excimer radiation laser were determined for $\mathrm{NH}_{3}$ at temper-atures up to $3500 \mathrm{~K}$ [5]. Measurements of the $\mathrm{NH}_{3}$ absorption coefficients at $\mathrm{CO}_{2}$ laser wavelengths have been done by Zelinger et al. [5] using photoacoustic spectroscopy. $\mathrm{NH}_{3}$ absorption coefficients were also measured by Allario and Seals [6] using several transitions of a $\mathrm{CO}_{2}$ laser for small concentrations of $\mathrm{NH}_{3}$ perturbed by $\mathrm{N}_{2}$. The influence of $\mathrm{CO}_{2}$ Laser line width on the measured absorption coefficients of atmospheric ammonia has been studied by Voitsekhovskaya et al. [7].

The focus of the present study is to present absorption line profile measurements of $\mathrm{NH}_{3}$ in the $6 \mu \mathrm{m}$ region $\left({ }^{P} P\right.$ branch of the $v_{4}$ band). In this range, we resolved the spectra for different $J$ and $K$ quantum numbers. We have determined the absorption coefficients in the centers and in the wings of $\mathrm{NH}_{3}$ lines self-perturbed and perturbed by $\mathrm{N}_{2}$ at various pressures (10-160 Torr). The measurements were made for different gas temperatures $235,245,268$, and $296 \mathrm{~K}$. The analysis was made as a function of $J$ and $K$ quantum numbers, and the results were compared to the previous investigations. 
TABLE 1: Experimental parameters.

\begin{tabular}{lccc}
\hline Studied gas & Temperature $(\mathrm{K})$ & $\begin{array}{c}\text { Pressure of the } \\
\text { perturbed gas } \\
(\text { mbar })\end{array}$ & $\begin{array}{c}\text { Cell length } \\
(\mathrm{cm})\end{array}$ \\
\hline $\mathrm{NH}_{3}-\mathrm{NH}_{3}$ & 296 & $10 \sim 141$ & 2.5 \\
$\mathrm{NH}_{3}-\mathrm{N}_{2}$ & $235,245,268,296$ & $10 \sim 141$ & 15 \\
\hline
\end{tabular}

\section{Experimental}

The measurements were made using a high-resolution Bruker Fourier transform spectrometer (Bruker IFS $120 \mathrm{HR}$ ) $[8,9]$. This spectrometer is equipped with different components: a Globar source, a KBr beam splitter, a filter eliminating infrared radiation above $2500 \mathrm{~cm}^{-1}$, and a photovoltaic $\mathrm{HgCdTe}$ detector cooled at $77 \mathrm{~K}$ by liquid nitrogen.

The spectral resolution was about $0.0038 \mathrm{~cm}^{-1}$ after apodization with a triangular function. This value is equal to the half-width at half maximum of the apparatus function approximated in the calculations by a Gaussian shape. This approximation has a negligible contribution to systematic errors since the pressure-broadened lines were much larger $[2,10]$. Ammonia gas in natural abundances was provided by Air Liquid France with stated purity of $98.5 \%$. The spectra were measured at different pressures covering the lines of the ${ }^{P} \mathrm{P}$ branch of the $\nu_{4}$ band of ammonia. $\mathrm{NH}_{3}$ and $\mathrm{N}_{2}$ gases were contained in a metallic cell with a $2.5 \mathrm{~cm}$ path length for $\mathrm{NH}_{3}$ self-perturbed, and in a Pyrex glass cell with a $15 \mathrm{~cm}$ path length for $\mathrm{NH}_{3}$ perturbed by $\mathrm{N}_{2}$. Both of the absorption cells are sealed by $\mathrm{CaF}_{2}$ windows.

The pressures of the gases were measured accurately using three calibrated capacitive MKS Baratron transducers with full-scale readings of 10, 100, and 1000 mbar. The accuracy of these manometers is $0.5 \%$ of the readout. Ammonia sample pressures were allowed to stabilize for sufficient time before the spectrum of the sample was finally recorded.

For $\mathrm{NH}_{3}$ self-perturbed, the pressure was varied from 5 to 120 mbar, whereas for $\mathrm{NH}_{3}$ perturbed by $\mathrm{N}_{2}$ we varied the gas pressure from 10 to 160 Torr. For the present experiments, the temperatures varies from 235 to $296 \mathrm{~K}$. Each temperature was monitored by three calibrated thermocouples (Pt-100).

The measured intensity of the incident light $\left(I_{0}\right)$ and the transmitted light $(I)$ at wave-number $\sigma$ were converted to transmission spectra $\tau(\sigma, T)$ using Lambert-Beer's law

$$
\tau(\sigma, T)=\frac{I(\sigma, T)}{I_{0}(\sigma, T)} .
$$

Table 1 summarizes the experimental parameters. The spectral region for this study is between 1470 and $1600 \mathrm{~cm}^{-1}$. Figure 1 shows short transmittance spectra of $\mathrm{NH}_{3}$ around $1550 \mathrm{~cm}^{-1}$ exhibiting some prominent lines of the ${ }^{P} P$ branch. These spectra were recorded at $T=296 \mathrm{~K}$. At low pressure, the lines are separated, but when the pressure increases the lines widen and begin to overlap.

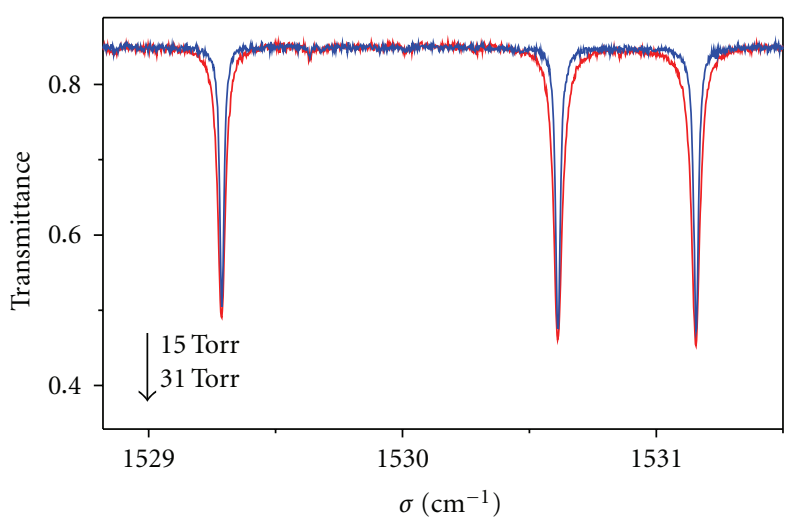

FIGURE 1: Transmittance spectrum of $\mathrm{NH}_{3}$ around $1550 \mathrm{~cm}^{-1}$ showing some lines of the ${ }^{P} P$ branch of the $\nu_{4}$ band. The pressures of $\mathrm{NH}_{3}$ are 15 and $31 \mathrm{mb}$.

\section{Fitting Procedures}

The absorption coefficient of an isolated line of the $v_{4}$ band is obtained by comparing the recorded line with a synthetic line. The adjustment is performed using the Rosenkranz profile given $[11,12]$ by

$$
\alpha(\sigma)=\frac{P_{\mathrm{NH}_{3}}}{\pi} \sum_{\text {line } \mathrm{k}} S_{k} \frac{P Y_{k}\left(\sigma-\sigma_{k}\right)+P \gamma_{k}}{\left(\sigma-\sigma_{k}\right)^{2}+\left(P \gamma_{k}\right)^{2}},
$$

where $P_{\mathrm{NH} 3}$ is the $\mathrm{NH}_{3}$ pressure, $P$ is the partial pressure of the perturbing gas, $k$ represents the line $v_{i} J_{i} \rightarrow v_{f} J_{f}$, $S_{k}$ its intensity, $\sigma_{k}$ its wave number including the collisional shift $\delta\left(\delta=\sigma_{k}-\sigma_{0}, \sigma_{0}\right.$ the unperturbed or zero pressure wave number), $\gamma_{k}$ its broadening coefficient, and $Y_{k}$ its mixing parameter.

The modelled transmission $\tau(\sigma)$ is the result of a convolution of $\alpha(\sigma)$ with a Doppler profile $\left(\alpha_{\text {Dop }}\right)$ and the apparatus function of the spectrometer $\left(F_{\text {App }}\right)[10]$.

$$
\begin{aligned}
& \tau(\sigma) \\
& =\int_{-\infty}^{+\infty} F_{\mathrm{App}}\left(\sigma-\sigma^{\prime}\right) \exp \left[-l \int_{-\infty}^{+\infty} \alpha_{\mathrm{Dop}}\left(\sigma^{\prime}-\sigma^{\prime \prime}\right) \alpha\left(\sigma^{\prime \prime}\right) d \sigma^{\prime \prime}\right] d \sigma^{\prime},
\end{aligned}
$$

where $l$ represents the length of the absorption cell.

The differences between the experimental and calculated spectra were minimized by adjusting the parameters $P S_{k}, \sigma_{k}$, $P \gamma_{k}$, and $P Y_{k}$ using a nonlinear least-squares multipressure fitting technique where all spectra at various pressures are successively adjusted using (3). An example of multipressure fit in the case of ${ }^{P} P(7,3)_{s}$ line for four $\mathrm{NH}_{3}$ pressures $(30,60$, 91, and 120 mbar) is shown in Figure 2. Residual (measured minus calculated) spectra are shown in the lower part of graphs.

As illustrated by this figure, the theoretical model given by (3) proves sufficiently accurate to fit very well the observed spectral lines without accounting for Dicke narrowing and/ or speed dependence and demonstrates at the same time that the line coupling cannot be neglected. 


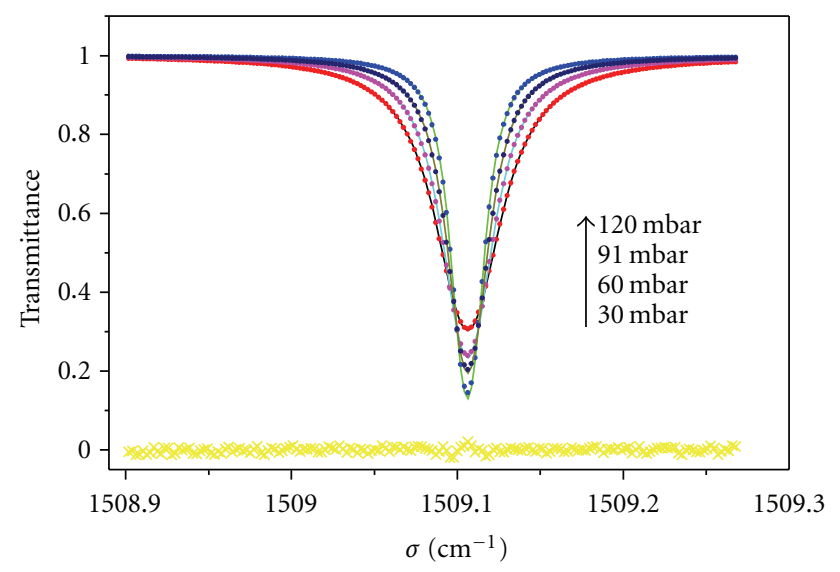

Figure 2: Results of multipressure fits for the ${ }^{P} P(7,3)_{s}$ line in the $\nu_{4}$ band of $\mathrm{NH}_{3}$ self-perturbed at $296 \mathrm{~K}$. (-) and $(\bullet)$ are the measured and calculated values, respectively. Residual (measured minus calculated) spectra are shown in the lower part of the graphs.

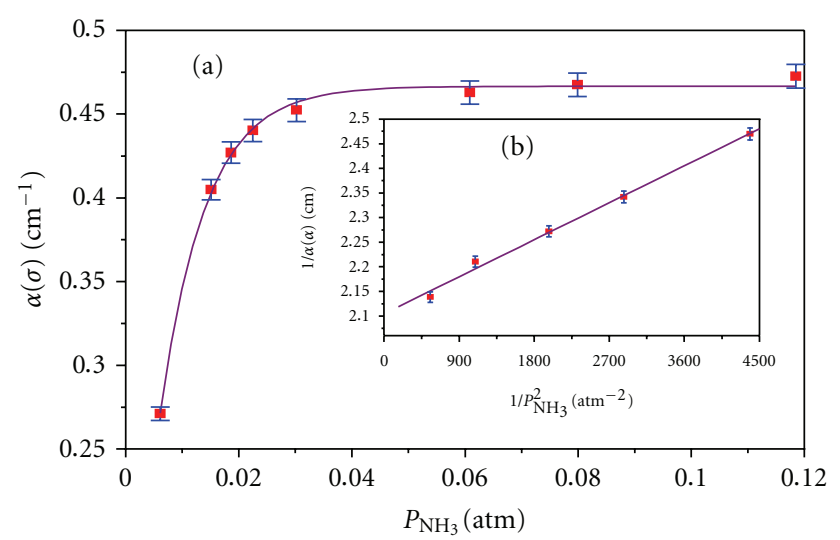

Figure 3: Variation of the absorption coefficient and its inverse in the center of the ${ }^{P} P(8,3)_{s}$ line versus $P_{\mathrm{NH} 3}$ and $1 / P_{\mathrm{NH} 3}^{2}$, respectively, at $T=296 \mathrm{~K}$.

\section{Results Analysis}

4.1. Line Center Absorption Coefficients. We have made measurements of the absorption coefficients for 60 isolated lines of $\mathrm{NH}_{3}$ in the spectral region between 1470 and $1600 \mathrm{~cm}^{-1}$. For illustration, the evolution of the absorption coefficient à $T=296 \mathrm{~K}$ for the ${ }^{P} P(8,3)_{s}$ line at various pressures of $\mathrm{NH}_{3}$ is shown in Figure 3(a).

In the low-pressure regime, we notice that the absorption coefficient of a given line varies as a quadratic function of pressure as given by the following equation:

$$
\alpha=C^{\text {te }} P_{\mathrm{NH}_{3}}^{2},
$$

where $C^{\text {te }}$ is a constant value depending on the individual line.

This figure shows that at high-pressure region, the absorption coefficient tends towards a constant value and hence becomes independent of pressure.

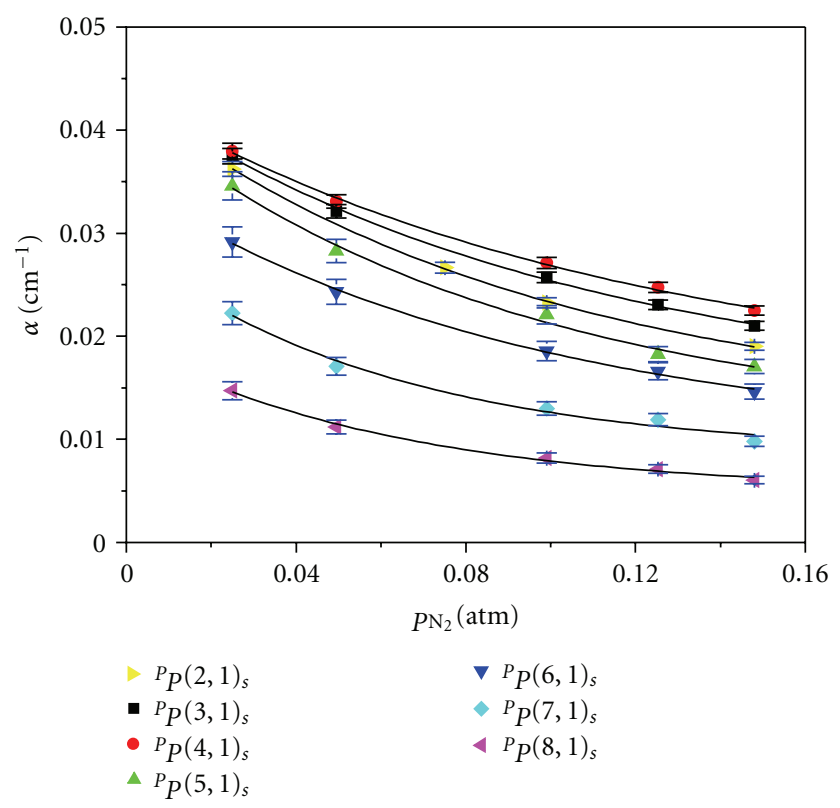

FIGURE 4: Variation of the absorption coefficient in the line center versus the $\mathrm{N}_{2}$ pressure $\left(P_{\mathrm{N} 2}\right)$ for the ${ }^{P} P(J, 1)_{s}$ lines.

These results are in agreement with those published in [4], where the author studied some lines of the $v_{2}$ band of $\mathrm{NH}_{3}$.

The inverse of the absorption coefficient $(1 / \alpha)$ as a function of the square of the $\mathrm{NH}_{3}$ pressure is plotted in Figure 3(b) for the ${ }^{P} P(8,3)$ s line. Indeed, one can see that these two parameters vary linearly. The slope of the obtained straight line is related to the line intensity and self-broadening coefficient of the considered line [4].

Results obtained for $\mathrm{NH}_{3}$ perturbed by $\mathrm{N}_{2}$, show that the peak absorption coefficient, for the 60 lines studied in this work, is decreasing with the $\mathrm{N}_{2}$ pressure. Figure 4 illustrates the variation of the line center absorption coefficients versus the $\mathrm{N}_{2}$ pressure for the ${ }^{P} P(J, 1)_{s}$ lines at $T=296 \mathrm{~K}$. This figure also shows that the absorption coefficient $\alpha$ decreases with the pressure of the perturbing gas. Moreover, it illustrates that $\alpha$ decreases with quantum number $J$ for a given $K$. For example, the $\alpha$ of ${ }^{P} P(2.1)_{s}$ line is greater than that of ${ }^{P} P(8,1)$ s line.

Figure 5 represents the evolution of the absorption coefficient $\alpha$ with the quantum number $J$ in the case of $\mathrm{NH}_{3}-\mathrm{NH}_{3}$ gas mixture at $T=296 \mathrm{~K}$ and $P=32$ Torr. The coefficient $\alpha$ has a maximum at $J=4$ for the ${ }^{P} P(J, 1)$ lines and decreases monotonically for $K \geq 2$ with increasing $J$.

According to the literature $[10,13]$, the line intensity $S_{0}$ depends on the statistical weight factor $g_{s}$, which is related to the quantum numbers $J$ and $K$. The intensities of the transition having a statistical weight $g_{s}=2$ (i.e., for $K=3 n, n=$ $1,2,3, \ldots)$ are generally higher than of those lines having a statistical weight $g_{s}=1$ for $K \neq 3 n$. As illustrated by Table 4 , one can conclude that the absorption coefficients and the line intensities vary in the same way as a function of the quantum numbers. 
TABLE 2: Self-absorption coefficient of the two wings of ${ }^{P} P(5,2)_{s}$ and ${ }^{P} P(7,4)_{s}$ lines as a function of the square of $\mathrm{NH}_{3}$ pressure $\left(P_{\mathrm{NH}}^{2}\right)$ at $T=296 \mathrm{~K}$.

\begin{tabular}{lcccc}
\hline$P_{\mathrm{NH}_{3}}^{2} \times 10^{4}\left(\mathrm{~atm}^{2}\right)$ & \multicolumn{3}{c}{$\alpha \times 10^{4}\left(\mathrm{~cm}^{-1}\right)$} & ${ }^{P} P(7,4)_{a \text { left }}$ \\
\hline 2.28 & ${ }^{P} P(5,2)_{s \text { left }}$ & ${ }^{P} P(5,2)_{s \text { right }}$ & - & ${ }^{P} P(7,4)_{a \text { right }}$ \\
18 & 14.9 & 14.4 & 48.5 & 1.64 \\
37 & 61 & - & 80.5 & 81.5 \\
63 & 123.8 & 125.9 & 122.1 & 121.5 \\
140 & 191.5 & 191.5 & 256.5 & 256.3 \\
\hline
\end{tabular}

TABle 3: Absorption coefficient of two wings of the ${ }^{P} P(7,2)_{a}$ for $\mathrm{NH}_{3}-\mathrm{N}_{2}$ mixtures as a function of $\mathrm{N}_{2}$ pressure $\left(P_{\mathrm{N}_{2}}\right)$ at $T=268 \mathrm{~K}$.

\begin{tabular}{llc}
\hline$P_{\mathrm{N}_{2}} \times 10^{3}(\mathrm{~atm})$ & \multicolumn{2}{c}{$\alpha / P_{\mathrm{NH}_{3}} \times 10^{2}\left(\mathrm{~cm}^{-1} \mathrm{~atm}^{-1}\right)$} \\
\hline 29.6 & 15.1 & ${ }^{P} P(7,2)_{a}$ left \\
59.2 & 19.4 & 13.8 \\
89.6 & 24.1 & 18.4 \\
121.9 & 27.7 & 23.9 \\
138.9 & 30.8 & 26.7 \\
\hline
\end{tabular}

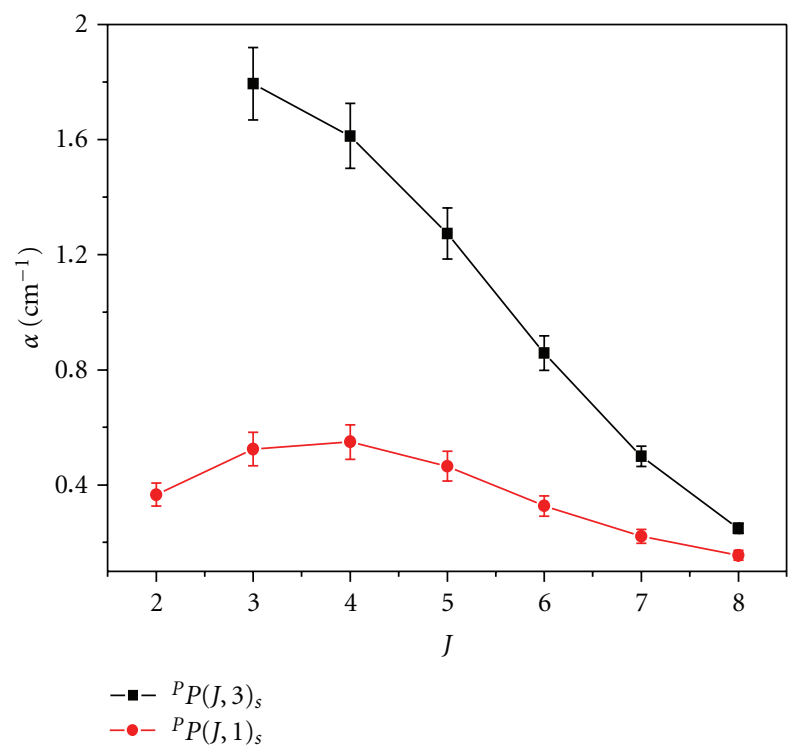

Figure 5: Variation of the absorption coefficient of ${ }^{P} P(J, 3)_{a}$ and ${ }^{P} P(J, 1)_{s}$ lines with the quantum numbers $J$ and $K$. Case of $\mathrm{NH}_{3}-$ $\mathrm{NH}_{3}$ gas mixture at $P=32$ Torr for $T=295 \mathrm{~K}$.

4.2. Line Wing Absorption Coefficients. According to our analysis, we observe a quadratic dependence of the absorption coefficient as a function of pressure of the $\mathrm{NH}_{3}$ gas that can be modeled as follows [14]:

$$
\alpha=A_{0}(\sigma, T) P_{\mathrm{NH}_{3}}^{2},
$$

$A_{0}(\sigma, T)$ is the normalized absorption coefficient depending on the temperature and the wave number $\sigma$ of the line; $P_{\mathrm{NH}_{3}}$ is the $\mathrm{NH}_{3}$ pressure. Table 2 gives the self-absorption coefficient of the two wings of ${ }^{P} P(5,2)_{s}$ and ${ }^{P} P(7,4)_{s}$ lines

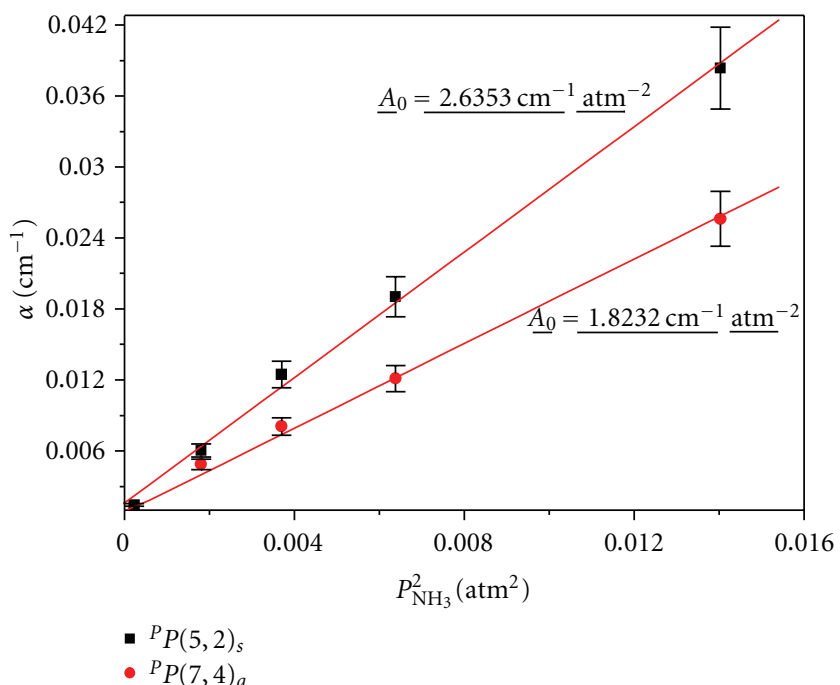

FIGURE 6: Variation of self-absorption coefficient in the right wings of ${ }^{P} P(5,2)_{s}$ and ${ }^{P} P(7,4)_{a}$ lines as a function of the square of $\mathrm{NH}_{3}$ pressure $\left(P_{\mathrm{NH}_{3}}^{2}\right)$ : Case of $\mathrm{NH}_{3}-\mathrm{NH}_{3}$ gas mixture at $T=296 \mathrm{~K}$.

as a function of the square of $\mathrm{NH}_{3}$ pressure $\left(P_{\mathrm{NH}_{3}}^{2}\right)$ at $T=$ 296 K. Figure 6 shows the variation of self-absorption coefficient of the right wings of ${ }^{P} P(5,2)_{s}$ and ${ }^{P} P(7,4)_{a}$ lines as a function of the square of $\mathrm{NH}_{3}$ pressure $\left(P_{\mathrm{NH}_{3}}^{2}\right)$. One can see that the wing absorption coefficients increase linearly with pressure.

All the self-absorption coefficients measured for the pressure and temperature ranges considered in this study validate the above quadratic pressure dependence given by (5).

For $\mathrm{NH}_{3}-\mathrm{N}_{2}$ gas mixtures, a sample of the absorption coefficient $\alpha$ for the two wings of the ${ }^{P} P(7,2)_{a}$ line as a function of $\mathrm{N}_{2}$ pressure $\left(P_{\mathrm{N}_{2}}\right)$ at $T=268 \mathrm{~K}$ is given by Table 3 . This table reveals an increasing of $\alpha$ with $P_{\mathrm{N}_{2}}$. So the coefficient $\alpha$ can be described by the following equation [15]:

$$
\alpha=A_{0}(\sigma, T) P_{\mathrm{NH}_{3}}^{2}+B_{0}(\sigma, T) P_{\mathrm{NH}_{3}} P_{\mathrm{N}_{2}},
$$

where $B_{0}(\sigma, T)$ is the normalized absorption coefficient.

The $A_{0}(\sigma, T)$ and $B_{0}(\sigma, T)$ parameters were determined using (6) and the absorption coefficient values for the right and left wings of the each line considered in this work. The results at $T=296 \mathrm{~K}$ are given in Table 4 for 32 ro-vibrational antisymmetric lines in the ${ }^{P} P$ branch of the $v_{4}$ band along with the estimated errors given in parentheses. 
TABLE 4: Values of the normalized absorption coefficients $A_{0}$ and $B_{0}$ for $\mathrm{NH}_{3}$ broadened by $\mathrm{N}_{2}$ at $T=296 \mathrm{~K}$.

\begin{tabular}{|c|c|c|c|c|c|}
\hline \multirow{2}{*}{ Transition } & \multirow{2}{*}{$\sigma\left(\mathrm{cm}^{-1}\right)$} & \multicolumn{2}{|c|}{$\mathrm{NH}_{3}-\mathrm{NH}_{3}$} & \multicolumn{2}{|c|}{$\mathrm{NH}_{3}-\mathrm{N}_{2}$} \\
\hline & & $A_{0}\left(\mathrm{~cm}^{-1} \mathrm{~atm}^{-2}\right)\left(\sigma_{\text {left }}\right)$ & $A_{0}\left(\mathrm{~cm}^{-1} \mathrm{~atm}^{-2}\right)\left(\sigma_{\text {right }}\right)$ & $B_{0}\left(\mathrm{~cm}^{-1} \mathrm{~atm}^{-2}\right)\left(\sigma_{\text {left }}\right)$ & $B_{0}\left(\mathrm{~cm}^{-1} \mathrm{~atm}^{-2}\right)\left(\sigma_{\text {right }}\right)$ \\
\hline${ }^{P} P(2,1)_{a}$ & 1591.1050 & $1.467(0.098)$ & $1.493(0.063)$ & $2.731(0.437)$ & $2.448(0.245)$ \\
\hline${ }^{P} P(2,2)_{a}$ & 1595.0801 & $6.759(0.348)$ & $1.045(0.069)$ & $3.228(0.233)$ & $2.799(0.303)$ \\
\hline${ }^{P} P(3,1)_{a}$ & 1572.4882 & $3.282(0.139)$ & $3.435(0.065)$ & $2.807(0.100)$ & $2.956(0.542)$ \\
\hline${ }^{P} P(3,3)_{a}$ & 1579.6363 & $16.39(0.431)$ & $2.216(0.047)$ & $3.859(0.274)$ & $4.176(0.183)$ \\
\hline${ }^{P} P(4,1)_{a}$ & 1554.7340 & $2.065(0.047)$ & $2.009(0.050)$ & $3.490(0.329)$ & $3.006(0.207)$ \\
\hline${ }^{P} P(4,2) a$ & 1558.2494 & $1.344(0.046)$ & $1.370(0.011)$ & $2.815(0.269)$ & $2.923(0.218)$ \\
\hline${ }^{P} P(4,3)_{a}$ & 1561.3835 & $4.217(0.086)$ & $4.1741(0.150)$ & $9.782(0.707)$ & $9.632(0.462)$ \\
\hline${ }^{P} P(4,4)_{a}$ & 1564.0825 & $10.40(0.186)$ & $0.566(0.042)$ & $2.338(0.203)$ & $5.111(0.511)$ \\
\hline${ }^{P} P(5,1)_{a}$ & 1538.0102 & $0.860(0.083)$ & $0.838(0.058)$ & $3.693(0.372)$ & $3.343(0.171)$ \\
\hline${ }^{P} P(5,2)_{a}$ & 1541.0041 & $2.520(0.075)$ & $2.272(0.021)$ & $2.883(0.540)$ & $2.893(0.534)$ \\
\hline${ }^{P} P(5,3)_{a}$ & 1543.8550 & $2.468(0.07)$ & $2.990(0.029)$ & $5.638(0.248)$ & $5.391(0.583)$ \\
\hline${ }^{P} P(5,4)_{a}$ & 1546.3315 & $5.805(0.194)$ & $4.610(0.270)$ & $4.829(0.028)$ & $4.013(0.539)$ \\
\hline${ }^{P} P(5,5)_{a}$ & 1548.4290 & $13.527(0.381)$ & $2.471(0.142)$ & $2.920(0.220)$ & $3.510(0.208)$ \\
\hline${ }^{P} P(6,1)_{a}$ & 1522.3847 & $1.370(0.033)$ & $1.518(0.024)$ & $2.020(0.384)$ & $1.021(0.134)$ \\
\hline${ }^{P} P(6,2)_{a}$ & 1522.7763 & - & - & $2.006(0.399)$ & $1.894(0.064)$ \\
\hline${ }^{P} P(6,3)_{a}$ & 1527.0615 & $2.822(0.093)$ & $2.583(0.053)$ & $4.232(0.364)$ & $4.313(0.372)$ \\
\hline${ }^{P} P(6,4)_{a}$ & 1529.2897 & $1.524(0.015)$ & $1.553(0.058)$ & $2.424(0.146)$ & $2.172(0.221)$ \\
\hline${ }^{P} P(6,5)_{a}$ & 1531.1590 & $1.571(0.07)$ & $1.4164(0.056)$ & $3.784(0.522)$ & $3.003(0.625)$ \\
\hline${ }^{P} P(6,6)_{a}$ & 1532.6831 & $20.697(0.570)$ & $2.250(0.118)$ & $4.430(0.076)$ & $9.116(0.919)$ \\
\hline${ }^{P} P(7,2)_{a}$ & 1509.4479 & $1.818(0.053)$ & $1.863(0.108)$ & $1.415(0.044)$ & $1.445(0.055)$ \\
\hline${ }^{P} P(7,3)_{a}$ & 1511.3125 & $1.169(0.064)$ & $1.510(0.047)$ & $1.183(0.195)$ & $1.312(0.247)$ \\
\hline${ }^{P} P(7,4)_{a}$ & 1513.0439 & $1.823(0.094)$ & $1.888(0.074)$ & $1.657(0.131)$ & $1.431(0.442)$ \\
\hline${ }^{P} P(7,5)_{a}$ & 1514.6055 & $2.319(0.176)$ & $2.145(0.141)$ & $1.810(0.157)$ & $1.500(0.104)$ \\
\hline${ }^{P} P(7,6)_{a}$ & 1515.8819 & $3.013(0.035)$ & $3.074(0.162)$ & $2.200(0.179)$ & $1.946(0.226)$ \\
\hline${ }^{P} P(7,7)_{a}$ & 1516.8521 & $8.994(0.217)$ & $1.248(0.070)$ & $2.080(0.120)$ & $2.632(0.091)$ \\
\hline${ }^{P} P(8,1)_{a}$ & 1494.2421 & $0.375(0.038)$ & $0.334(0.009)$ & $1.116(0.113)$ & $1.180(0.101)$ \\
\hline${ }^{P} P(8,2)_{a}$ & 1493.5269 & - & - & $1.145(0.142)$ & $1.328(0.215)$ \\
\hline${ }^{P} P(8,3)_{a}$ & 1496.1740 & $0.546(0.105)$ & $0.597(0.072)$ & $2.357(0.153)$ & $2.785(0.261)$ \\
\hline${ }^{P} P(8,4)_{a}$ & 1497.6750 & $1.982(0.104)$ & $2.123(0.071)$ & $4.054(0.261)$ & $4.521(0.276)$ \\
\hline${ }^{P} P(8,6)_{a}$ & 1499.8028 & $2.199(0.022)$ & $2.877(0.264)$ & $2.710(0.236)$ & $2.499(0.917)$ \\
\hline${ }^{P} P(8,7)_{a}$ & 1500.5103 & $11.869(1.307)$ & $10.742(1.414)$ & - & - \\
\hline${ }^{P} P(8,8)_{a}$ & 1500.9439 & $7.227(0.231)$ & $2.221(0.335)$ & $1.423(0.349)$ & $1.799(0.368)$ \\
\hline
\end{tabular}

These errors correspond to the statistical errors expressed as one-time standard deviation for all spectroscopic parameters determined in this work. As expected, the errors vary widely with the lines. The stronger and less blended ones are better determined. For the lines which are too weak or too strongly blended, no reliable fit could be obtained. For this reason, some lines have been disregarded. The assignments of the lines considered in this table are taken from [16]. Within the experimental errors, as seen by Table 4 , the values of $A_{0}(\sigma, T)$ and $B_{0}(\sigma, T)$ are practically identical for the two wings.

Figure 7 shows the variation of the absorption coefficient with the $\mathrm{N}_{2}$ pressure for the two wings of the ${ }^{P} P(7,2)_{a}$ line for $\mathrm{NH}_{3}-\mathrm{N}_{2}$ mixtures at $T=268 \mathrm{~K}$. As shown by this figure, the variation of the absorption coefficient divided by the $\mathrm{NH}_{3}$ pressure $\left(\alpha / P_{\mathrm{NH}_{3}}\right)$ with the $\mathrm{N}_{2}$ pressure is linear. Also, we observe that the values of $\alpha / P_{\mathrm{NH}_{3}}$ and $A_{0}(\sigma, T)$ parameters are practically the same for the left and right wings of the lines.

4.3. Temperature Dependence. Spectra of the $v_{4}$ band of $\mathrm{NH}_{3}$ perturbed by $\mathrm{N}_{2}$ were recorded at four temperatures 235 , 245,268 , and $296 \mathrm{~K}$ for different pressures of nitrogen $\left(P_{\mathrm{N}_{2}}\right)$. For these spectra, the pressure of $\mathrm{NH}_{3}$ was fixed. Variation of the absorption coefficient $\alpha$ at the line center as a function of $P_{\mathrm{N}_{2}}$ for the ${ }^{P} P(5,2)_{s}$ line for $T=235$ and $265 \mathrm{~K}$ is shown by Figure 8 which illustrates a decreasing of the absorption coefficient with temperature.

According to Shi and Zhang and Bauer et al. [17, 18], the temperature dependence of absorption coefficient $\alpha(T)$ could be presented by the simple power law:

$$
\alpha=\alpha\left(T_{0}\right)\left(\frac{T}{T_{0}}\right)^{A}
$$




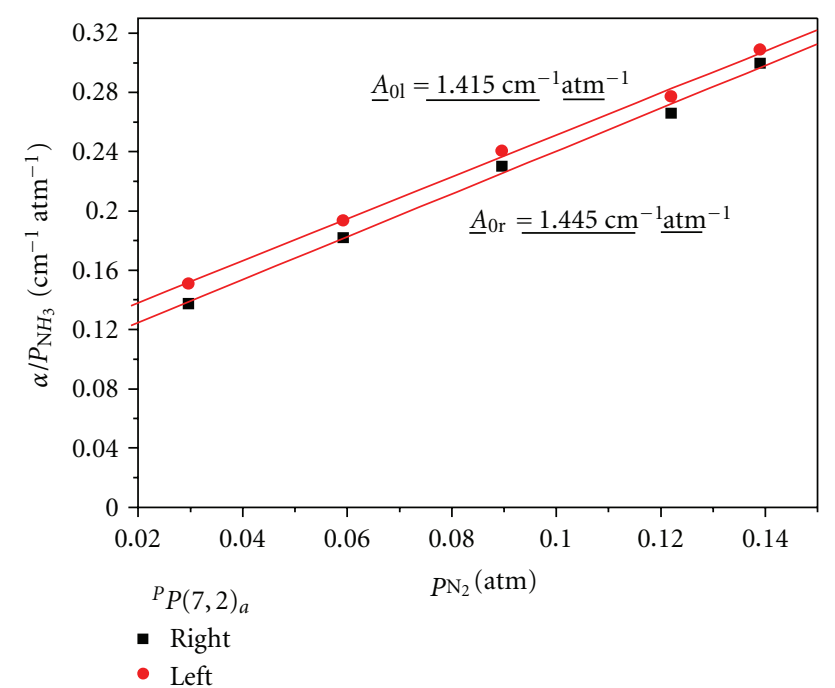

FIgURE 7: Variation of $\alpha / P_{\mathrm{NH}_{3}}$ versus the $\mathrm{N}_{2}$ pressure $\left(P_{\mathrm{N} 2}\right)$ for the two wings of the ${ }^{P} P(7,2)_{a}$ line perturbed by $\mathrm{N}_{2}$ at $T=268 \mathrm{~K}$.

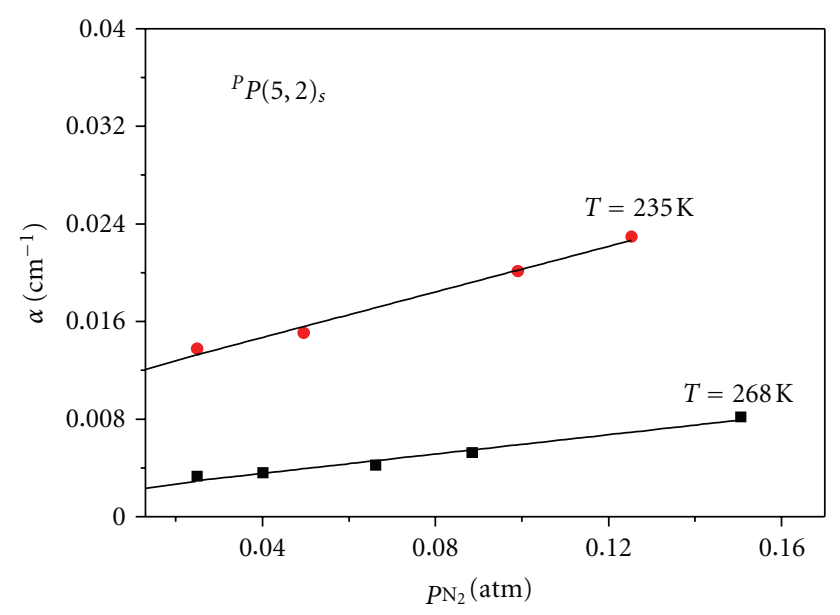

FIgURE 8: Variation of the absorption coefficient as a function of the $\mathrm{N}_{2}$ pressure $\left(P_{\mathrm{N} 2}\right)$ for the ${ }^{P} P(5,2)$ s line for the temperatures $T=$ 235 and $265 \mathrm{~K}$.

where $A$ is the temperature exponent and $T_{0}$ is the reference temperature. In our case $T_{0}=235 \mathrm{~K}$.

From the measured values of the absorption coefficients for the considered temperatures, one can determine the values of the exponent $A$ as the slope of least square fits from the graphs of $\ln \left(T / \alpha\left(T_{0}\right)\right)$ as a function of $\ln \left(T / T_{0}\right)$. The straight lines obtained for all the transitions considered in this work validate (7) within the indicated temperature range. Figure 9 illustrates the variation of $\ln [\alpha(T) / \alpha(235)]$ as a function of $\ln (T / 235)$ for the ${ }^{P} P(5,2)_{a}$ line. The variation is linear; the slope of the line obtained from a linear regression gives a temperature exponent $A=-0.619 \pm 0.016$.

This dependence is in agreement with the work performed by Bauer et al. [18] in their study of the temperature dependence of the absorption coefficient of $\mathrm{H}_{2} \mathrm{O}$ transitions.

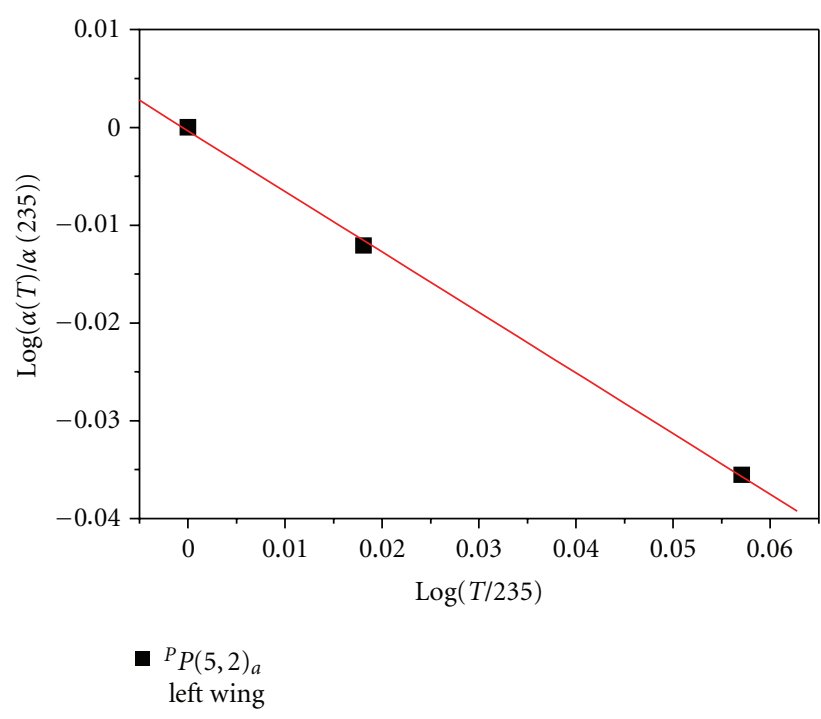

FIGURE 9: Variation of $\ln [\alpha(T) / \alpha(235)]$ as a function of $\ln (T / 235)$ for the left wing of ${ }^{P} P(5,2)_{a}$ line. The slope of the line obtained from a linear regression represents the temperature exponent $A=$ $-0.619 \pm 0.016$.

\section{Conclusion}

Using spectra recorded using a Fourier transform spectrometer and a multispectrum fitting technique, we have determined the absorption coefficients at the center and in the wings of 60 lines pertaining to the ${ }^{P} P$ branch of the $\nu_{4}$ band of $\mathrm{NH}_{3}$ as a function of $\mathrm{NH}_{3}$ and $\mathrm{N}_{2}$ pressures for different temperatures. The present results are in agreement with other recent measurements. In the low-pressure region, the self-absorption coefficient at the center of a given line varies with pressure as a quadratic function. At higher pressures, this coefficient tends to become constant. For $\mathrm{NH}_{3}-\mathrm{N}_{2}$ mixture, the values of the absorption coefficients exhibit a decreasing with $\mathrm{N}_{2}$ pressure.

In the wings of the lines, these coefficients show an increasing with the square of $\mathrm{NH}_{3}$ pressure, while for $\mathrm{NH}_{3}-\mathrm{N}_{2}$ gas mixtures they increase with $\mathrm{N}_{2}$ pressure.

For this gas mixture, we have studied the temperature dependence of absorption coefficient which fits closely an exponential low. The temperature exponents of this law were derived for the ${ }^{P} P(5,2)_{a}$ line.

\section{References}

[1] H. Aroui, S. Nouri, and J. P. Bouanich, " $\mathrm{NH}_{3}$ self-broadening coefficients in the $v_{2}$ and $v_{4}$ bands and line intensities in the $v_{2}$ band," Journal of Molecular Spectroscopy, vol. 220, no. 2, pp. 248-258, 2003.

[2] S. Nouri, J. Orphal, H. Aroui, and J. M. Hartmann, “Temperature dependence of pressure broadening of $\mathrm{NH}_{3}$ perturbed by $\mathrm{H}_{2}$ and $\mathrm{N}_{2}$," Journal of Molecular Spectroscopy, vol. 227, no. 1, pp. 60-66, 2004.

[3] D. F. Davidson, A. Y. Chang, K. Kohse-Höinghaus, and R. K. Hanson, "High temperature absorption coefficients of $\mathrm{O}_{2}$, $\mathrm{NH}_{3}$, and $\mathrm{H}_{2} \mathrm{O}$ for broadband ArF excimer laser radiation," 
Journal of Quantitative Spectroscopy and Radiative Transfer, vol. 42, no. 4, pp. 267-278, 1989.

[4] K. Benzerhouni, Absorption spectroscopy of ammonia and study of the laser $\left({ }^{15} \mathrm{NH}_{3}+\mathrm{N}_{2}\right)$ for population inversion, Ph.D. thesis, Orsay, France, 1988.

[5] Z. Zelinger, I. Jancik, and P. Engst, "Measurement of the $\mathrm{NH}_{3}$, $\mathrm{CCl}_{2} \mathrm{~F}_{2}, \mathrm{CHClF}_{2}, \mathrm{CFCl}_{3}$, and $\mathrm{CClF}_{3}$ absorption coefficients at isotopic ${ }^{13} \mathrm{C}^{16} \mathrm{O}_{2}$ laser wavelengths by photoacoustic spectroscopy," Applied Optics, vol. 31, no. 33, pp. 6974-6975, 1992.

[6] F. Allario and R. K. Seals, "Measurements of $\mathrm{NH}_{3}$ absorption coefficients with a $\mathrm{C}^{13} \mathrm{O}_{2}^{16}$ laser," Applied Optics, vol. 14, no. 9, pp. 2229-2233, 1975.

[7] O. K. Voitsekhovskaya, E. N. Aksenova, and F. G. Shatrov, "Influence of $\mathrm{CO}_{2}$-laser linewidth on the measured absorption coefficients of atmospheric water vapor and ammonia," Applied Optics, vol. 38, no. 12, pp. 2337-2341, 1999.

[8] P. Jacquinot, "The luminosity of spectrometers with prisms, gratings, or Fabry Perot etalons," The Journal of the Optical Society of America, vol. 44, pp. 761-765, 1954.

[9] A. Predoi-Cross, G. C. Mellau, R. M. Lees, and B. P. Winnewisser, "Fourier transform infrared spectroscopy of the first CO-stretch overtone band of ${ }^{13} \mathrm{CH}_{3} \mathrm{OH}$," Journal of Molecular Spectroscopy, vol. 189, no. 2, pp. 144-152, 1998.

[10] S. Hadded, H. Aroui, J. Orphal, J. P. Bouanich, and J. M. Hartmann, "Line broadening and mixing in $\mathrm{NH}_{3}$ inversion doublets perturbed by $\mathrm{NH}_{3}, \mathrm{He}, \mathrm{Ar}$, and $\mathrm{H}_{2}$," Journal of Molecular Spectroscopy, vol. 210, no. 2, pp. 275-283, 2001.

[11] P. W. Rosenkranz, "Shape of the $5 \mathrm{~mm}$ oxygen band in the atmosphere," IEEE Transactions on Antennas and Propagation, vol. 23, no. 4, pp. 498-506, 1975.

[12] A. Lévy, N. Lacome, and C. Chackerian Jr., Spectroscopy of the Earth's Atmosphere and Interstellar Medium, Academic Press, New York, NY, USA, 1992.

[13] H. Aroui, S. Nouri, and J. P. Bouanich, " $\mathrm{NH}_{3}$ self-broadening coefficients in the $v 2$ and $v 4$ bands and line intensities in the $v 2$ band," Journal of Molecular Spectroscopy, vol. 220, no. 2, pp. 248-258, 2003.

[14] R. Le Doucen, C. Cousin, C. Boulet, and A. Henry, "Temperature dependence of the absorption in the region beyond the 4.3-'m band head of $\mathrm{CO}_{2}$. 1: pure $\mathrm{CO}_{2}$ case," Applied Optics, vol. 24, no. 6, pp. 897-906, 1985.

[15] C. Cousin, R. Le Doucen, C. Boulet, and A. Henry, "Temperature dependence of the absorption in the region beyond the 4.3-' $\mathrm{m}$ band head of $\mathrm{CO}_{2}$. 2: $\mathrm{N}_{2}$ and $\mathrm{O}_{2}$ broadening," Applied Optics, vol. 24, no. 22, pp. 3899-3907, 1985.

[16] H. Sasada, Y. Endo, E. Hirota, R. L. Poynter, and J. S. Margolis, "Microwave and Fourier-transform infrared spectroscopy of the $v 4=1$ and $v 2=2$ s states of $\mathrm{NH}_{3}$," Journal of Molecular Spectroscopy, vol. 151, no. 1, pp. 33-53, 1992.

[17] G. Shi and H. Zhang, "The relationship between absorption coefficient and temperature and their effect on the atmospheric cooling rate," Journal of Quantitative Spectroscopy and Radiative Transfer, vol. 105, no. 3, pp. 459-466, 2007.

[18] A. Bauer, M. Godon, J. Carlier, Q. Ma, and R. H. Tipping, "Absorption by $\mathrm{H}_{2} \mathrm{O}$ and $\mathrm{H}_{2} \mathrm{O}-\mathrm{N}_{2}$ mixtures at $153 \mathrm{GHz}$," Journal of Quantitative Spectroscopy and Radiative Transfer, vol. 50, no. 5, pp. 463-475, 1993. 


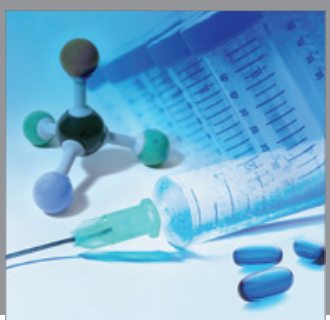

International Journal of

Medicinal Chemistry

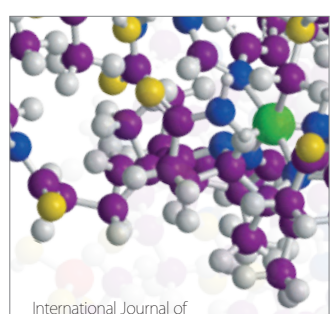

Carbohydrate Chemistry

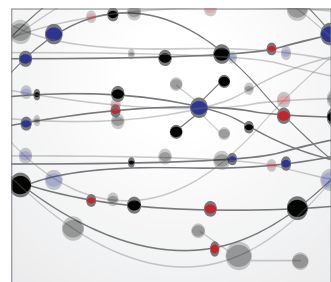

The Scientific World Journal
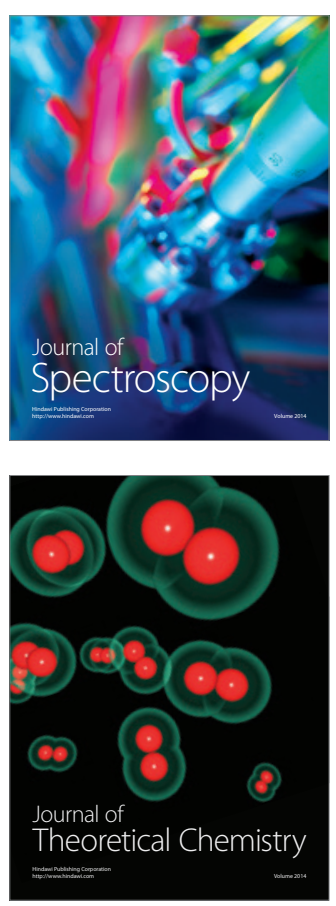
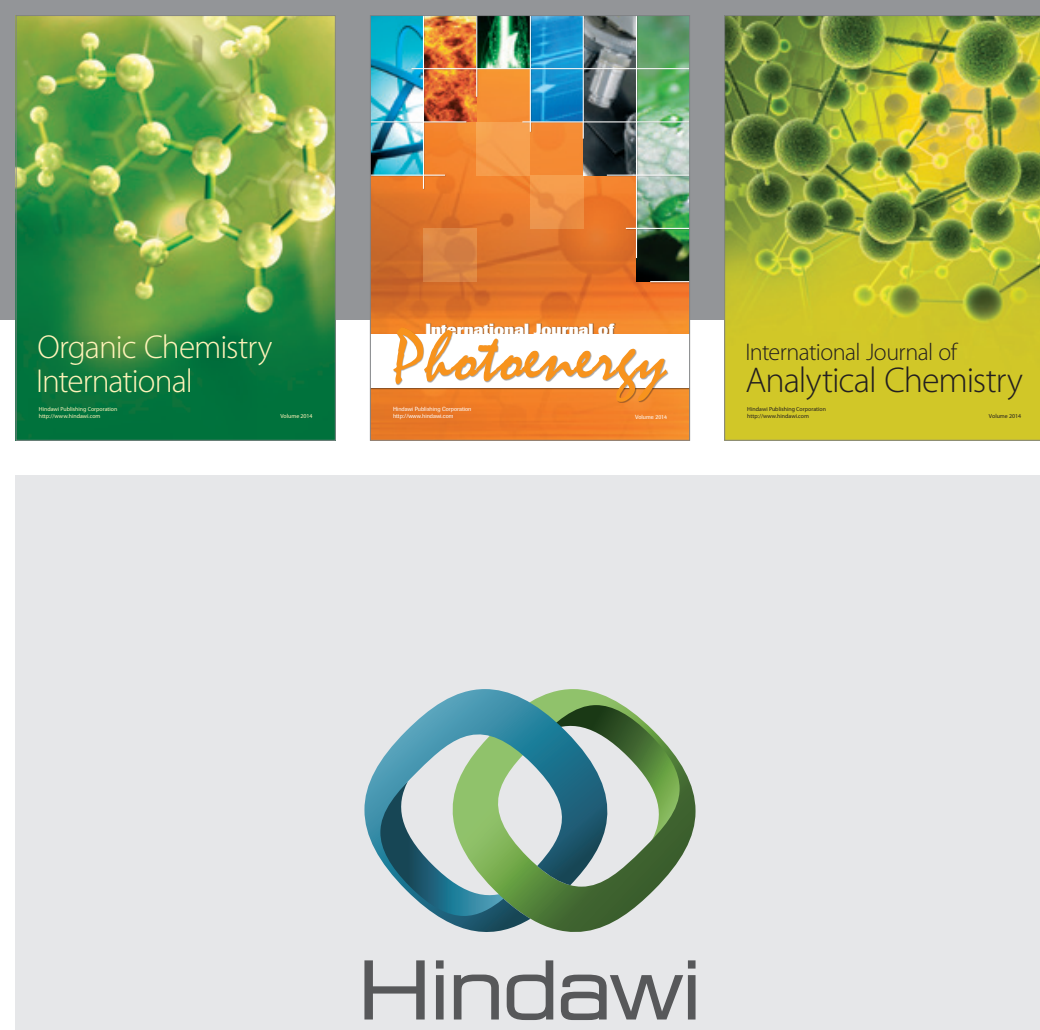

Submit your manuscripts at

http://www.hindawi.com
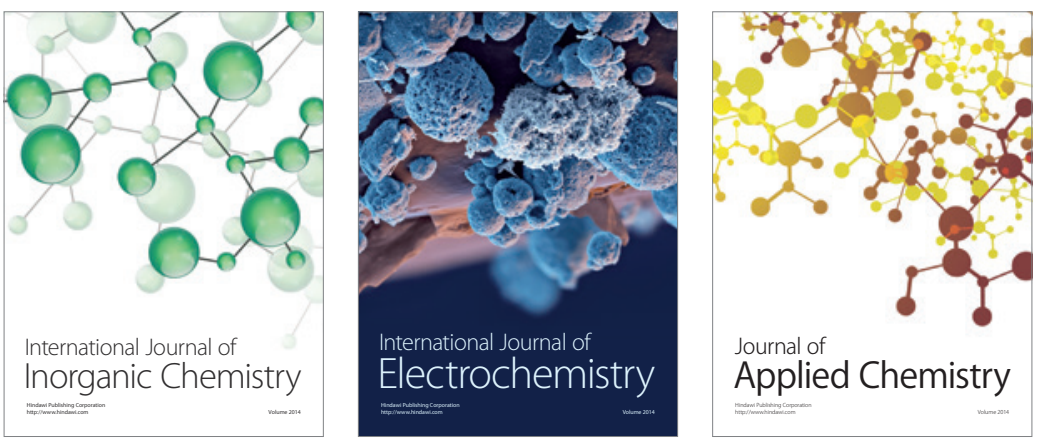

Journal of

Applied Chemistry
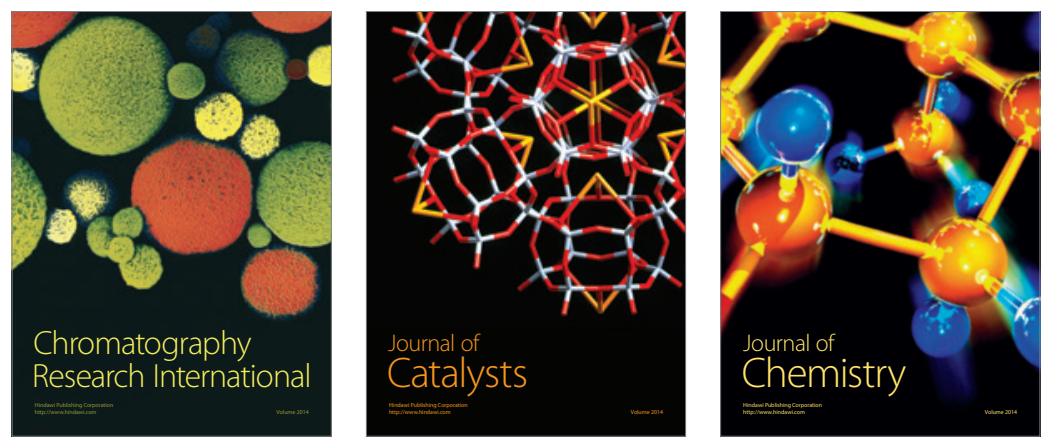
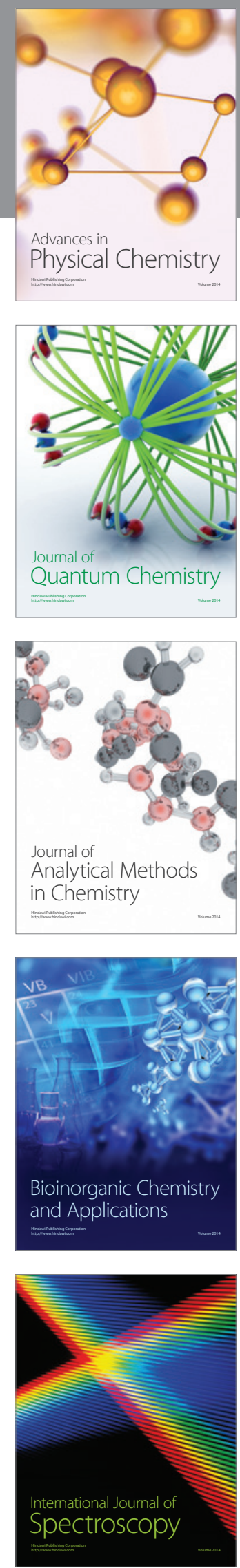